\title{
Dehydration process influences the phenolic profile, antioxidant and antimicrobial properties of Galium aparine L.
}

\author{
Sylwia Senio ${ }^{\mathrm{a}}$, Carla Pereira ${ }^{\mathrm{a}}$, Josiana Vaz ${ }^{\mathrm{a}}$, Marina Sokovic ${ }^{\mathrm{b}}$, Lillian Barros ${ }^{\mathrm{a}, *}$, \\ Isabel C.F.R. Ferreira ${ }^{\mathrm{a}, *}$ \\ a Centro de Investigação de Montanha (CIMO), Instituto Politécnico de Bragança, Campus de Santa Apolónia, 5300-253, Bragança, Portugal \\ ${ }^{\mathrm{b}}$ University of Belgrade, Department of Plant Physiology, Institute for Biological Research "Siniša Stanković, Bulevar Despota Stefana 142, 11000, Belgrade, Serbia
}

\section{A R T I C L E I N F O}

\section{Keywords:}

Galium aparine L.

Dehydration process

Phenolic compounds

Bioactive properties

\begin{abstract}
A B S T R A C T
Galium aparine L. is a very disseminated plant in temperate zones, commonly known as clivers or bedstraw, belonging to the Rubiaceae family and it is traditionally used for its medicinal applications. In this study, $G$. aparine hydromethanolic extracts and infusions were prepared from air-dried and freeze-dried samples in order to assess their phenolic profile, antioxidant, antimicrobial, and cytotoxic properties. All the studied extracts revealed a similar phenolic profile, but the hydromethanolic extract obtained from the freeze-dried sample presented the highest concentration of phenolic compounds, followed by the respective infusion and the airdried sample hydromethanolic extract. The major compound detected in the extracts was 5-O-caffeoylquinic acid (from 145 to $163 \mathrm{mg} / \mathrm{g}$ extract). Regarding the bioactivity, in general, the extracts presenting higher phenolic concentrations also revealed enhanced bioactive properties. The $\mathrm{EC}_{50}$ values obtained in the antioxidant activity assays ranged from 13.5 to $884 \mu \mathrm{g} / \mathrm{mL}$, with the freeze-dried sample hydromethanolic extract presenting the highest activity $(13.5-555 \mu \mathrm{g} / \mathrm{mL})$. Similar conclusions could be made in terms of antimicrobial properties, with this extract showing the lowest MIC (1.85-15 mg/mL), MBC (3.75-7.5 mg/mL), and MFC (3.75-20 mg/mL) values. None of the extracts revealed cytotoxicity. The results obtained in this study suggested that $G$. aparine extracts can be a good source of phenolic compounds with antioxidant and antimicrobial properties.
\end{abstract}

\section{Introduction}

There are 350,000 plant species in the world, among which about 80,000 edible and yet, it is estimated that only about 150 species are cultivated, directly for human consumption or as a feed for animals (Füleky, 2009). Numerous plant species that could provide excellent sources of foodstuff as part of a balanced diet, pharmaceutical products, insecticides, food additives such as colorants and flavourings, or even a raw ingredient for the preparation of beverages, remain underutilized (Haq, 1993).

It is well-known that polyphenol-rich foods and beverages may increase plasma antioxidant capacity, and plants are considered rich sources of these secondary metabolites, with a variety of more than 8000 such compounds identified from various plant species (Pandey and Rizvi, 2009). Moreover, epidemiological data indicates that the long term consumption of diets rich in plant polyphenols offers a protection against the development of cancers, diabetes, osteoporosis, cardiovascular and neurodegenerative diseases (Pandey and Rizvi, 2009; Young and Woodside, 2001). The ability of these natural antioxidants to delay oxidation processes in foodstuffs and biological membranes has recently focused much attention (Lindsey et al., 2002; Vlase et al., 2014), which has led to an increased antioxidant assessment of many medicinal and food plant species (Abbasi et al., 2015). In this matter, the traditional knowledge plays an essential role on the identification of plants that may be useful, however, in many instances most of this knowledge survives in the people's memory and is now in danger of disappearing (Fabricant and Farnsworth, 2001; Fennell et al., 2004; Jyotsna and Katewa, 2016).

Galium aparine L. (Rubiaceae), commonly known as clivers or bedstraw is a common weed in temperate zones on all continents and in Europe, it occurs from Portugal in the west to Russia in the east, and from the UK in the north to Italy in the south (CABI, 2018). It is an unwanted and troublesome plant species in cereal, rapeseed and sugar beet fields where it is noted for its detrimental impact on the potential yields (Malik and Born, 1988). Traditionally, G. aparine has enjoyed a large number of medicinal applications for diverse health conditions. Briefly, the whole herb (stem, leaf, flower and seed) has been commonly used as cooling diuretic in fevers and for urinary tract infections,

\footnotetext{
* Corresponding authors.

E-mail addresses: lillian@ipb.pt (L. Barros), iferreira@ipb.pt (I.C.F.R. Ferreira).
} 
in skin diseases such as eczema or psoriasis, ulcers, chronic sores, as a blood purifier i.e., to increase lymphatic flow, to reduce swellings, infection and inflammation, or to stop bleeding from wounds (Tobyn et al., 2016).

Beyond these applications, in Sweden, roasted seeds of $G$. aparine were used as a coffee substitute (Malik and Born, 1988) and in Turkey, young shoots of $G$. aparine are also eaten roasted (Taskin and Bitis, 2016) and used to coagulate milk, being known as "yogurt herb" (Aslantürk et al., 2017; Deliorman et al., 2001). Although the herb has long history of its use in phytotherapy, and the contemporary time's herbalists continue to use it as a diuretic, the pharmacological evidence supporting this efficiency is scarce. According to some reports, this plant is a source of polyphenols (Moubasher et al., 2016; Vlase et al., 2014), phytosterols (Mocan et al., 2016), alkaloids, anthraquinones, saponins (Aslantürk et al., 2017), sesquiterpenoids, squalene, aromatic compounds, higher alkanes (and derivatives), fatty acids, chlorophylls, carotenoids and iridoids (Deliorman et al., 2001; Goryacha et al., 2014).

In order to establish scientific rationale for the use of $G$. aparine, the first aim of this study was to investigate the phenolic profile, antioxidant, antimicrobial and cytotoxic properties of hydromethanolic extracts and infusions prepared from this plant species. Furthermore, since medicinal plants are often dried and sold as semi- and processed products, in this study, a freshly harvested botanical material was prepared by air-drying and freeze-drying with the objective of examining the effect of the drying method on the phenolic composition and bioactive properties of $G$. aparine.

\section{Material and methods}

\subsection{Samples and samples preparation}

Galium aparine L. (Rubiaceae) was collected at various growth stages in order to prepare a homogeneous sample, in June 2017, from the campus of the Polytechnic Institute of Bragança, Portugal. The collected plant material was authenticated by Professor of Botany Carlos Aguiar and a specimen voucher was deposited in the herbarium of the School of Agriculture, Polytechnic Institute of Bragança (Portugal).

The vegetal material (leaves, stems, flowers and seeds) was subjected to two drying methods, i.e., air-drying (one week, at room temperature, in the dark) and freeze-drying (lyophilisation; FeeeZone 4.5, Labconco, Kansas City, MO, USA). The dried samples were reduced to fine and homogeneous powder $(\sim 20$ mesh) and stored at room temperature, protected from direct light, for further analysis.

\subsection{Extracts preparation}

For each sample, infusions and hydromethanolic extracts were prepared in order to compare the phenolic composition and bioactive properties of extracts obtained from different procedures, using thermal and nonthermal extractions, and solvents with different polarities, once the extracted compounds are dependent of these conditions. Regarding infusions, air-dried and freeze-dried samples $(1 \mathrm{~g})$ were infused with freshly boiled distilled water $(100 \mathrm{~mL})$, left aside for $5 \mathrm{~min}$ and subsequently filtered through filter paper. The resulting extracts were then freeze-dried and a yield of 21.9 and $27.4 \%$ was obtained for air-dried and freeze-dried samples, respectively.

For the preparation of the hydromethanolic extracts, the samples $(1 \mathrm{~g})$ were extracted by stirring $(150 \mathrm{rpm})$ with $30 \mathrm{~mL}$ of methanol:water $(80: 20, v / v)$ at room temperature for $1 \mathrm{~h}$, and subsequently filtered through filter paper. The residue was then extracted with an additional $30 \mathrm{~mL}$ portion of methanol:water $(80: 20, \mathrm{v} / \mathrm{v})$ and filtered. Methanol was evaporated at $40^{\circ} \mathrm{C}$ under reduced pressure (Rotavac Valve Tec, Germany) and the remaining supernatant was freeze-dried. The extraction yield was of 23.9 and $22.7 \%$ for air-dried and freezedried samples, respectively.

\subsection{Phenolic compounds}

The phenolic profile was determined by LC-DAD-ESI/MSn (Dionex Ultimate 3000 UPLC, Thermo Scientific, San Jose, CA, USA). The lyophilized infusions and hydromethanolic extracts were re-dissolved in water and methanol/water mixture (80:20, v/v), respectively, at a concentration of $5 \mathrm{mg} / \mathrm{mL}$. Double online detection was used using a DAD (280, 330, and $370 \mathrm{~nm}$ as preferred wavelengths) and in a mass spectrometer in negative mode, equipped with an ESI source (Linear Ion Trap LTQ XL mass spectrometer, Thermo Finnigan, San Jose, CA, USA), as previously described by Bessada et al. (2016).

The identification of the phenolic compounds was performed using standard compounds, when available, by comparing their retention times, UV-vis and mass spectra; and also comparing the obtained information with available data reported in the literature, giving a tentative identification, when no standards were available. For quantitative analysis, calibration curves $(5-100 \mu \mathrm{g} / \mathrm{mL})$ for each available phenolic standard (5-O-caffeoylquinic acid $\geq 99 \%, \quad p$-coumaric acid $\geq 90 \%$, ferulic acid $\geq 90 \%$, and quercetin-3-O-rutinoside $\geq 99 \%$ HPLC purity, Extrasynthèse, Genay, France) were constructed based on the UV signal. For the identified phenolic compounds for which a commercial standard was not available, the quantification was performed through the calibration curve of the most similar available standard (Table 1). The results were expressed as $\mathrm{mg} / \mathrm{g}$ of extract.

\subsection{Antioxidant activity}

For the antioxidant activity assessment, the lyophilized infusions and hydromethanolic extracts were re-dissolved in water and methanol/water mixture $(80: 20, \mathrm{v} / \mathrm{v})$, respectively, at a final concentration of $10 \mathrm{mg} / \mathrm{mL}$. These stock solutions were further diluted to perform the bellow described assays.

\subsubsection{DPPH radical-scavenging activity assay}

DPPH radical-scavenging activity was assessed using BioTek ELX800 microplate Reader (Bio-Tek Instruments, Inc.; Winooski, USA). The reaction mixture in each of the 96 wells consisted of the infusions and hydromethanolic extracts at different concentrations $(30 \mu \mathrm{L})$ and methanolic solution $(270 \mu \mathrm{L})$ containing DPPH radicals $\left(6 \times 10^{-5} \mathrm{~mol} /\right.$ L). The mixture was left to stand for $60 \mathrm{~min}$ in the dark and at room temperature. The absorbance was measured at $515 \mathrm{~nm}$ to assess the reduction of DPPH radicals, which was calculated as a percentage of DPPH discolouration using the formula: $\left[\left(\mathrm{A}_{\mathrm{DPPH}}-\mathrm{A}_{\mathrm{S}}\right) / \mathrm{A}_{\mathrm{DPPH}}\right] \times 100$, where $A_{S}$ is the absorbance of the solution containing the sample, and $\mathrm{A}_{\text {DPPH }}$ is the absorbance of the DPPH solution (Rita et al., 2016).

\subsubsection{Reducing power}

In order to assess the capacity to convert $\mathrm{Fe}^{3+}$ into $\mathrm{Fe}^{2+}$, samples solutions at different concentrations $(0.5 \mathrm{~mL})$ were mixed with sodium phosphate buffer $(200 \mathrm{mmol} / \mathrm{L}, \mathrm{pH} 6.6,0.5 \mathrm{~mL})$ and potassium ferricyanide $(1 \% \mathrm{w} / \mathrm{v}, 0.5 \mathrm{~mL})$. The resulting mixtures were incubated at $50^{\circ}$ $\mathrm{C}$ for $20 \mathrm{~min}$, and trichloroacetic acid $(10 \% \mathrm{w} / \mathrm{v}, 0.5 \mathrm{~mL})$ was added. The supernatant $(0.8 \mathrm{~mL})$ was then poured in a 46 -well microplate along with deionised water $(0.8 \mathrm{~mL})$ and ferric chloride $(0.1 \% \mathrm{w} / \mathrm{v})$. The reducing power was assessed through the absorbance at $690 \mathrm{~nm}$, using the microplate reader mentioned above (Rita et al., 2016).

\subsubsection{Inhibition of $\beta$-carotene bleaching assay}

The $\beta$-carotene bleaching inhibition was assessed by measuring the capacity of the extracts and infusions to neutralise linoleate free radicals. A $\beta$-carotene solution was obtained by dissolving $\beta$-carotene $(2 \mathrm{mg})$ in chloroform $(10 \mathrm{~mL})$, and evaporated (Rotavac Valve Tec, Germany) in a round bottom flask at $40{ }^{\circ} \mathrm{C}$ under reduced pressure. Linoleic acid $(0.2 \mathrm{~g})$, Tween $80(2 \mathrm{~g})$ and distilled water $(0.5 \mathrm{~L})$ were added to the flask with vigorous shaking. Aliquots $(4.8 \mathrm{~mL})$ of the resulting emulsion were transferred into the test tubes containing 


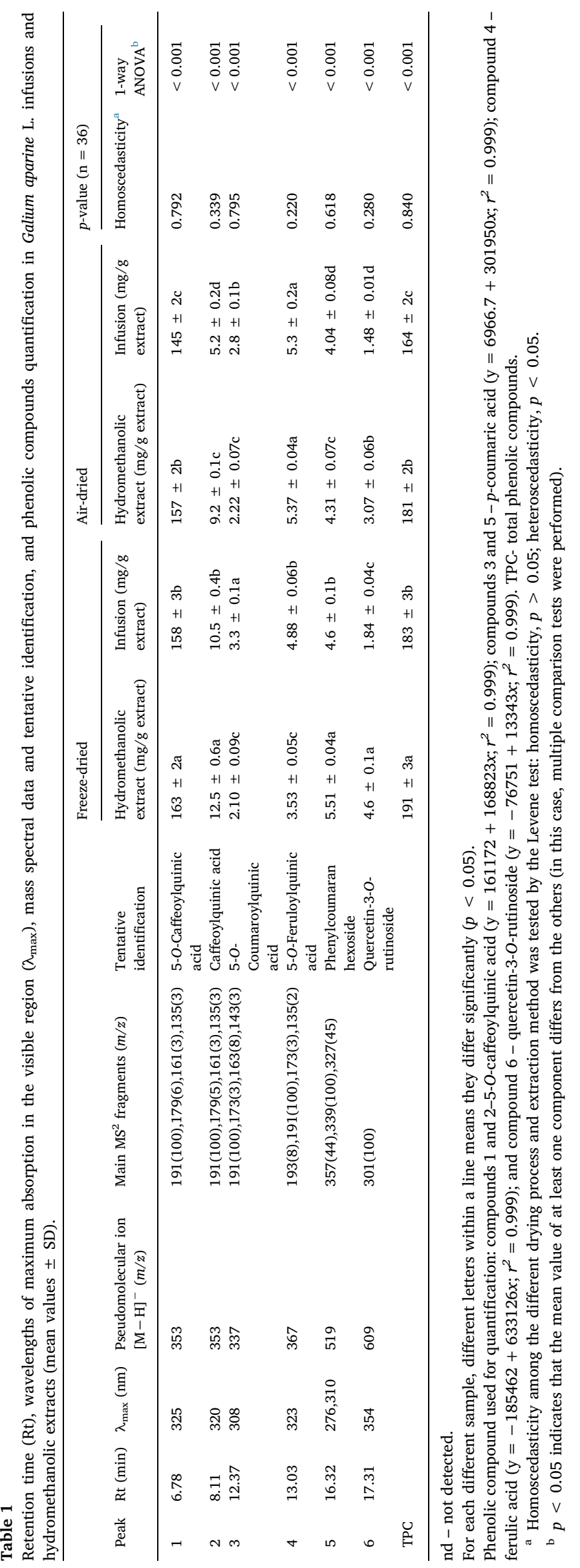


different concentrations of infusions and hydromethanolic extracts, vortexed and the absorbance (T0) was measured at $470 \mathrm{~nm}$. After $2 \mathrm{~h}$ of incubation at $50{ }^{\circ} \mathrm{C}$ in a water bath with agitation $(100 \mathrm{rpm})$, the absorbance (T1) was measured again. $\beta$-carotene bleaching inhibition was calculated using the equation: Absorbance (T1) - Absorbance (T0) $\times 100$ (Rita et al., 2016).

\subsubsection{Lipid peroxidation inhibition by thiobarbituric acid reactive substance (TBARS) assay}

The porcine (Sus scorfa) brain tissue was obtained from local slaughter house, dissected and homogenized with cold Tris- $\mathrm{HCl}$ (20 mM, pH 7.4) buffer solution. The brain tissue homogenate was produced in ratio $1: 2 \mathrm{w} / \mathrm{v}$ and centrifuged at $3000 \mathrm{~g}$ for $10 \mathrm{~min}$. An aliquot $(100 \mu \mathrm{L})$ of the supernatant was incubated with the sample solutions at different concentrations in the presence of $\mathrm{FeSO}_{4}(10 \mathrm{mM}$, $100 \mu \mathrm{L})$ and ascorbic acid $(0.1 \mathrm{mM}, 100 \mu \mathrm{L})$ at $37^{\circ} \mathrm{C}$ for $1 \mathrm{~h}$. The reaction was stopped by the addition of trichloroacetic acid $(28 \% \mathrm{w} / \mathrm{v}$, $500 \mu \mathrm{L}$ ) and a solution of thiobarbituric acid (TBA, $2 \% \mathrm{w} / \mathrm{v}, 380 \mu \mathrm{L}$ ) was added. The samples were incubated at $80^{\circ} \mathrm{C}$ for $20 \mathrm{~min}$ and centrifuged $(3000 \mathrm{~g}, 5 \mathrm{~min})$ in order to remove precipitated proteins. The absorbance of the pink malondialdehyde (MDA)-TBA complex in the supernatant was measured at $532 \mathrm{~nm}$, and the inhibition ratio (\%) was determined using the equation: Inhibition ratio $(\%)=[(\mathrm{A}-\mathrm{B}) \times 100]$ where $\mathrm{A}$ is the absorbance of the control sample, and $\mathrm{B}$ is the absorbance of the sample solution (Svobodova et al., 2017).

\subsection{Cytotoxicity}

For the cytotoxicity assessment, the lyophilized infusions and hydromethanolic extracts were re-dissolved to a final concentration of $1000 \mu \mathrm{g} / \mathrm{mL}$. The hepatotoxicity was assessed using a non-tumour liver primary culture established in our laboratory, PLP2, prepared from a freshly harvested porcine liver obtained from a local slaughter house. The cell line was plated at $1.0 \times 10^{4}$ cells/well in 96-well plates and sulforhodamine B assay was performed according to a procedure previously described by the authors (Guimarães et al., 2013). The results were expressed in $\mathrm{GI}_{50}$ values (sample concentration that inhibited $50 \%$ of the net cell growth). Ellipticine was used as positive control.

\subsection{Antimicrobial activity}

For the antimicrobial activity assessment, the lyophilized infusions and hydromethanolic extracts were re-dissolved in 5\% DMSO, at a final concentration of $30 \mathrm{mg} / \mathrm{mL}$. These stock solutions were further diluted to perform the bellow described assays.

\subsubsection{Antibacterial activity}

Antibacterial activity was assessed against Gram-negative bacteria: Escherichia coli (ATCC 35210), Salmonella typhimurium (ATCC 13311), Salmonella enteritidis (ATCC 13076), Enterobacter cloacae (ATCC 35030), and Gram-positive bacteria: Staphylococcus aureus (ATCC 6538), Bacillus cereus (clinical isolate), Micrococcus flavus (ATCC 10240), and Listeria monocytogenes (NCTC 7973), following a previously described procedure (Soković et al., 2010). The minimum inhibitory (MIC) and minimum bactericidal (MBC) concentrations were determined according to the referred reference. Streptomycin and ampicillin were used as positive controls.

\subsubsection{Antifungal activity}

Antifungal activity was evaluated against Aspergillus fumigatus (ATCC 1022), Aspergillus ochraceus (ATCC 12066), Aspergillus versicolor (ATCC 11730), Aspergillus niger (ATCC 6275), Candida krusei (IBRS 1flac1), Penicillium funiculosum (ATCC 36839), Penicillium ochrochloron (ATCC 9112), and Penicillium verrucosum var. cyclopium (food isolate), following the procedure previously described by the authors (Soković and Van Griensven, 2006). The minimum inhibitory (MIC) and minimum fungicidal (MFC) concentrations were obtained following the same reference. Ketokonazole and bionazole were used as positive controls.

\subsection{Statistical analysis}

For each drying treatment (air-dried and freeze-dried), three independent samples were analysed and all assays were carried out in triplicate. Data were expressed as mean \pm standard deviation. A $5 \%$ significance level, using IBM SPSS Statistics for Windows, version 23.0. (IBM Corp., Armonk, NY, USA), was applied to all statistical tests. The fulfilment of the one-way ANOVA requirements, specifically the normal distribution of the residuals (data not shown) and the homogeneity of variance, was tested by means of the Shapiro Wilk's and the Levene's tests, respectively. Depending on the homoscedasticity, the dependent variables were compared using Tukey's honestly significant difference (HSD; when homoscedastic) or Tamhane's T2 multiple comparison (when no homoscedastic) tests.

\section{Results and discussion}

\subsection{Phenolic compounds}

Phenolic compounds identification was carried out considering their retention times, whenever possible in comparison with commercially available standards, and both UV and MS spectra. Data obtained by HPLC-DAD-ESI/MS analysis (retention time, $\lambda_{\max }$, pseudomolecular ion, main fragment ions in $\mathrm{MS}^{2}$ ), phenolic compounds identification, and respective quantification are present in Table 1 . Six compounds were found in $G$. aparine hydromethanolic extracts and infusions, among which four phenolic acids, a flavonol and a lignin. All the extracts revealed similar profiles, only differing in the detected compounds content. The freeze-dried sample hydromethanolic extract was the one revealing the highest total phenolic compounds concentration (191 mg/g extract; chromatogram shown in Fig. 1), followed by the respective infusion and the air-dried sample hydromethanolic extract that presented similar phenolic amounts (183 and $181 \mathrm{mg} / \mathrm{g}$ extract, respectively). The most abundant compound in all the assessed extracts was 5 - $O$-caffeoylquinic acid, in concentrations of about $85-88 \%$ of the total phenolic compounds content. All the compounds detected were present in higher amounts in the freeze-dried sample hydromethanolic extract, with the exception of 5-O-coumaroylquinic acid that was most abundant in this sample infusion $(3.3 \mathrm{mg} / \mathrm{g}$ extract), and 5 - $O$-feruloylquinic acid that was mostly detected in both air-dried sample extracts $(5.37 \mathrm{mg} / \mathrm{g}$ of hydromethanolic extract and $5.3 \mathrm{mg} / \mathrm{g}$ of infusion).

Compounds 1 (5-O-caffeoylquinic acid) and 6 (quercetin-3-O-rutinoside) were positively identified according to their retention time, mass, and UV-vis characteristics by comparison with commercial standards. These compounds were also previously detected in samples of $G$. aparine ethanolic extracts (Vlase et al., 2014). Compounds 2 (caffeoylquinic acid), 3 (5-O-coumaroylquinic acid), and 4 (5-O-feruloylquinic acid) were identified taking into account the recommended IUPAC numbering system (IUPAC, 1976) as also the hierarchical keys previously developed by Clifford et al. (2005, 2003). Compound 5, was tentatively identified as a lignin, taking into account the fragmentation patterns reported by Morreel et al. (2014), that also observed MS $^{2}$ fragments at $m / z 519$, followed by $m / z 357$ ( $-162 \mathrm{u}$ ) resulting from hexose loss, and $m / z 339(-18 u)$ and $327(-30 u)$ that could be explained by water and formaldehyde losses, respectively. According to the authors, these type I fragmentations are typically observed in the spectrum of phenylcoumarans, which has led to the tentative identification of this compound as phenylcoumaran hexoside.

In a study performed by Vlase et al. (2014), G. aparine ethanolic extracts presented six phenolic acids (caftaric, gentisic, caffeic, chlorogenic, p-coumaric, and ferulic acids) and five flavonoids (hyperoside, isoquercitrin, rutin, quercetin, and luteolin), with rutin, 


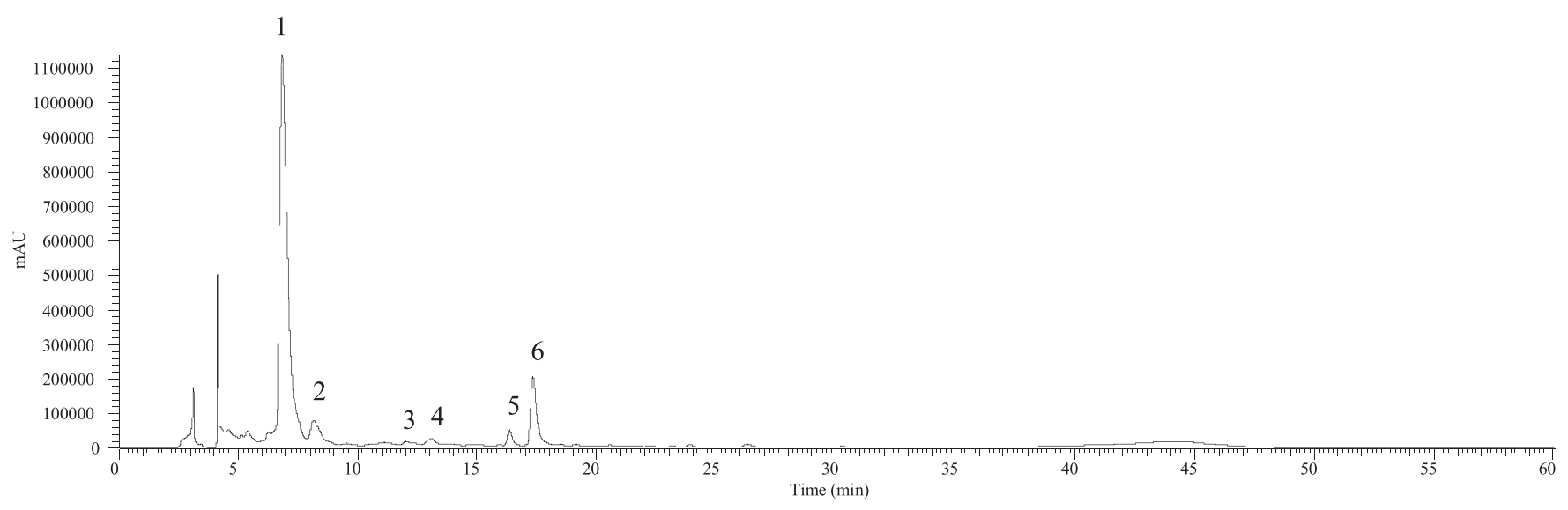

Fig. 1. Phenolic profile of Galium aparine L. freeze-dried sample hydromethanolic extract, recorded at $280 \mathrm{~nm}$. Peak numbering is in accordance with Table 1.

quercetin, and ferulic acid $(7.983,5.679$, and $3.793 \mathrm{mg} / 100 \mathrm{~g} \mathrm{dw}$, respectively) as the most abundant compounds. These authors also studied three other Galium species, namely Galium verum, Galium mollugo, and Galium odoratum and despite $G$. aparine presented the largest variety of phenolic compounds, $G$. verum was the species revealing the highest total phenolic concentration, followed by G. mollugo, G. aparine, and $G$. odoratum (894, 31, 21, and $17 \mathrm{mg} / 100 \mathrm{~g} \mathrm{dw}$, respectively). Other studies also evaluated G. aparine water extracts (Abbasi et al., 2015) and aqueous fractions (Bokhari et al., 2013) in terms of total phenolics and the water extracts contained $24 \mathrm{mg} \mathrm{GAE} / 100 \mathrm{~g}$ fw, whereas the aqueous fractions revealed a slightly lower amount of $22.1 \mathrm{mg} \mathrm{GAE} / \mathrm{g}$ of dried fraction.

\subsection{Antioxidant activity and cytotoxicity}

The antioxidant activity results of the $G$. aparine infusions and hydromethanolic extracts are presented in Table 2. In general, the freezedried sample hydromethanolic extract revealed lower $\mathrm{EC}_{50}$ values (ranging from 13.5 to $555 \mu \mathrm{g} / \mathrm{mL}$ ), indicating a stronger antioxidant activity, except for the DPPH scavenging activity assay, where the infusion obtained from the air-dried sample gave better results $\left(\mathrm{EC}_{50}\right.$ value of $467 \mu \mathrm{g} / \mathrm{mL}$ ). This latest also revealed higher reducing power and $\beta$-carotene bleaching inhibition capacity $\left(\mathrm{EC}_{50}\right.$ values of 267.7 and $109 \mu \mathrm{g} / \mathrm{mL}$, respectively) than the freeze-dried sample hydromethanolic extract and the air-dried sample infusion. Nevertheless, regarding the TBARS inhibition capacity, the air-dried sample hydromethanolic extract presented the best results ( $\mathrm{EC}_{50}$ value of $221 \mu \mathrm{g} / \mathrm{mL}$ ), following the freeze-dried sample hydromethanolic extract. Comparing the results obtained for the different extracts of $G$. aparine with those of trolox (positive control), the hydromethanolic extract of the freeze-dried sample was the only one revealing a lower $\mathrm{EC}_{50}$ value (13.5 and $23 \mu \mathrm{g}$ / $\mathrm{mL}$ for the extract and the positive control, respectively), in the TBARS inhibition assay. In a study performed with several $G$. aparine extract fractions, the butanol, methanol, and aqueous fractions revealed DPPH scavenging activity at $61.7,75$, and $58.3 \mu \mathrm{g} / \mathrm{mL}$, respectively, which represent concentrations ten times lower than those obtained in the present study (Bokhari et al., 2013). On the other hand, in a study performed by Abbasi et al. (2015), water and acetone extracts of $G$. aparine showed approximately 69 and 55\% DPPH scavenging activity, respectively, in concentrations of $100 \mathrm{mg} / \mathrm{mL} \mathrm{dw}$, but once again, it was not possible to compare these results to those achieved herein because of the methodology discrepancies along with the differences on the results analysis and presentation.

Regarding cytotoxicity evaluation (Table 2), none of the G. aparine extracts revealed toxicity in the assessed porcine liver cells primary culture, PLP2, at the studied concentration $(1000 \mu \mathrm{g} / \mathrm{mL})$, which support the use of this plant extracts without associated toxicity effects.

\subsection{Antimicrobial activity}

The results obtained in the screening of antimicrobial activity of $G$. aparine extracts against the studied bacteria and fungi are shown in Table 3. The antibacterial activity of the extracts was tested against eight bacterial strains: B. cereus, M. flavus, S. aureus, L. monocytogenes, E. coli, E. cloacae, $S$. enteritidis, and $S$. typhimurium. Generally, all the extracts revealed inhibitory and bactericidal capacity in concentrations

Table 2

Antioxidant activity and cytotoxicity of Galium aparine L. infusions and hydromethanolic extracts (mean values \pm SD).

\begin{tabular}{|c|c|c|c|c|c|c|c|}
\hline & \multicolumn{2}{|l|}{ Freeze-dried } & \multicolumn{2}{|l|}{ Air-dried } & \multicolumn{2}{|l|}{$p$-value $(\mathrm{n}=36)$} & \multirow[t]{2}{*}{ Positive control } \\
\hline & Hydromethanolic extract & Infusion & Hydromethanolic extract & Infusion & Homoscedasticity $^{\mathrm{a}}$ & 1-way ANOVA ${ }^{\mathrm{b}}$ & \\
\hline \multicolumn{8}{|c|}{ Antioxidant activity $\left(\mathrm{EC}_{50}\right.$ values, $\left.\mu \mathrm{g} / \mathrm{mL}\right)$} \\
\hline DPPH scavenging activity & $555 \pm 4 b$ & $554 \pm 11 b$ & $884 \pm 12 a$ & $467 \pm 3 c$ & 0.002 & $<0.001$ & $41 \pm 1$ \\
\hline Reducing power & $175.2 \pm 0.2 \mathrm{~d}$ & $327 \pm 1 b$ & $365 \pm 3 a$ & $267.7 \pm 0.6 c$ & 0.001 & $<0.001$ & $41.7 \pm 0.3$ \\
\hline$\beta$-carotene bleaching inhibition & $83 \pm 1 d$ & $128 \pm 4 b$ & $143 \pm 8 a$ & $109 \pm 2 c$ & 0.001 & $<0.001$ & $18 \pm 1$ \\
\hline TBARS inhibition & $13.5 \pm 0.8 \mathrm{~d}$ & $525 \pm 2 a$ & $221 \pm 3 c$ & $404 \pm 6 b$ & 0.001 & $<0.001$ & $23 \pm 1$ \\
\hline \multicolumn{8}{|l|}{ Citotoxicity ( $\mathrm{GI}_{50}$ values, $\mu \mathrm{g} / \mathrm{mL}$ ) } \\
\hline PLP2 & $>1000$ & $>1000$ & $>1000$ & $>1000$ & - & - & $3.2 \pm 0.7$ \\
\hline
\end{tabular}

nd - not detected.

Trolox and ellipticine were used as positive control for the antioxidant activity and cytotoxicity assays, respectively.

${ }^{a}$ Homoscedasticity among the different drying process and extraction method was tested by the Levene test: homoscedasticity, $p>0.05$; heteroscedasticity, $p<0.05$

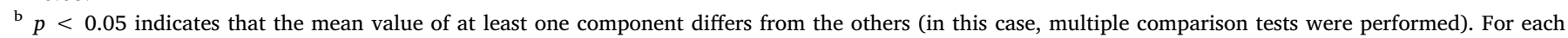
different sample, different letters within a line means they differ significantly $(p<0.05)$. 
Table 3

Antimicrobial activity of Galium aparine L. infusions and hydromethanolic extracts.

\begin{tabular}{|c|c|c|c|c|c|c|}
\hline & \multicolumn{2}{|l|}{ Freeze-dried } & \multicolumn{2}{|l|}{ Air-dried } & \multirow[t]{2}{*}{ Positive control 1} & \multirow[t]{2}{*}{ Positive control 2} \\
\hline & Hydromethanolic extract & Infusion & Hydromethanolic extract & Infusion & & \\
\hline \multicolumn{7}{|c|}{ Antibacterial activity (MIC and MBC values, mg/mL) } \\
\hline \multirow[t]{2}{*}{ Bacillus cereus } & 3.75 & 3.75 & 1 & 3.75 & 0.1 & 0.25 \\
\hline & 7.5 & 15 & 1.85 & 7.5 & 0.2 & 0.4 \\
\hline \multirow[t]{2}{*}{ Micrococcus flavus } & 3.75 & 3.75 & 3.75 & 3.75 & 0.2 & 0.25 \\
\hline & 7.5 & 15 & 7.5 & 7.5 & 0.3 & 0.4 \\
\hline \multirow[t]{2}{*}{ Staphylococcus aureus } & 1.85 & 3.75 & 3.75 & 10 & 0.04 & 0.25 \\
\hline & 3.75 & 15 & 7.5 & 20 & 0.1 & 0.45 \\
\hline \multirow[t]{2}{*}{ Listeria monocytogenes } & 1.85 & 10 & 3.75 & 7.5 & 0.2 & 0.4 \\
\hline & 7.5 & 20 & 15 & 20 & 0.3 & 0.5 \\
\hline \multirow[t]{2}{*}{ Escherichia coli } & 3.75 & $>30$ & 10 & $>30$ & 0.2 & 0.4 \\
\hline & 7.5 & $>30$ & 15 & $>30$ & 0.3 & 0.5 \\
\hline \multirow[t]{2}{*}{ Enterobacter cloacae } & 1.85 & 15 & 3.75 & 7.5 & 0.2 & 0.25 \\
\hline & 7.5 & 30 & 7.5 & 15 & 0.3 & 0.5 \\
\hline \multirow[t]{2}{*}{ Salmonella enteritidis } & 1.85 & 15 & 7.5 & 3.75 & 0.15 & 0.3 \\
\hline & 3.75 & 20 & 15 & 7.5 & 0.3 & 0.6 \\
\hline \multirow[t]{2}{*}{ Salmonella typhimurium } & 1.85 & 15 & 3.75 & 7.5 & 0.25 & 0.4 \\
\hline & 3.75 & 30 & 7.5 & 20 & 0.5 & 0.75 \\
\hline \multicolumn{7}{|c|}{ Antifungal activity (MIC and MFC values, $\mathrm{mg} / \mathrm{mL}$ ) } \\
\hline \multirow[t]{2}{*}{ Aspergillus fumigatus } & 15 & $>30$ & 7.5 & 30 & 0.25 & 0.15 \\
\hline & 20 & $>30$ & 15 & $>30$ & 0.5 & 0.2 \\
\hline \multirow[t]{2}{*}{ Aspergillus versicolor } & 1.85 & 7.5 & 3.75 & 15 & 0.2 & 0.1 \\
\hline & 3.75 & 15 & 7.5 & $>30$ & 0.5 & 0.2 \\
\hline \multirow[t]{2}{*}{ Aspergillus ochraceus } & 3.75 & 15 & 1.85 & 15 & 1.5 & 0.15 \\
\hline & 7.5 & 30 & 3.75 & $>30$ & 2 & 0.2 \\
\hline \multirow[t]{2}{*}{ Aspergillus niger } & 3.75 & $>30$ & 3.75 & $>30$ & 0.2 & 0.15 \\
\hline & 7.5 & $>30$ & 7.5 & $>30$ & 0.5 & 0.2 \\
\hline \multirow[t]{2}{*}{ Candida krusei } & 3.75 & $>30$ & 3.75 & 30 & 0.075 & 0.05 \\
\hline & 7.5 & $>30$ & 7.5 & $>30$ & 0.15 & 0.1 \\
\hline \multirow[t]{2}{*}{ Penicillium funiculosum } & 3.75 & 30 & 3.75 & 30 & 0.2 & 0.2 \\
\hline & 7.5 & $>30$ & 7.5 & $>30$ & 0.5 & 0.25 \\
\hline \multirow[t]{2}{*}{ Penicillium ochrochloron } & 3.75 & $>30$ & 10 & 30 & 2.5 & 0.2 \\
\hline & 7.5 & $>30$ & 15 & $>30$ & 3.5 & 0.25 \\
\hline \multirow[t]{2}{*}{ Penicillium verrucosum var. cyclopium } & 7.5 & $>30$ & 10 & 30 & 0.2 & 0.1 \\
\hline & 15 & $>30$ & 30 & $>30$ & 0.3 & 0.2 \\
\hline
\end{tabular}

MIC: Minimum Inhibitory concentration; MBC: Minimum bactericidal concentration; MFC: Minimal fungicidal concentration.

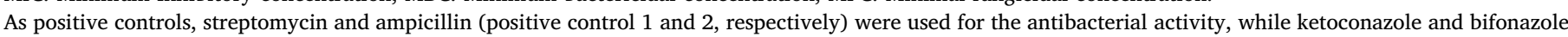
(positive control 1 and 2, respectively) were used for antifungal activity.

ranging from 1 to 15 and 1.85 to $30 \mathrm{mg} / \mathrm{mL}$, respectively. Nevertheless, the infusions did not show the capacity to inhibit $E$. coli, at the studied concentrations $(30 \mathrm{mg} / \mathrm{mL})$. The extract revealing higher antibacterial properties, with lowest MIC and MBC values, was the freeze-dried sample hydromethanolic extract, which inhibited $S$. aureus, L. monocytogenes, E. cloacae, $S$. enteritidis, and $S$. typhimurium growth in a concentration of $1.85 \mathrm{mg} / \mathrm{mL}$ and $B$. cereus, $M$. flavus, and $E$. coli at $3.75 \mathrm{mg} / \mathrm{mL}$. The MBC values presented by this extract varied from 3.75 to $7.5 \mathrm{mg} / \mathrm{mL}$. B. cereus was the strain revealing the highest sensitivity to the extracts, with MIC and MBC values of 1 and $1.85 \mathrm{mg} / \mathrm{mL}$ when exposed to the air-dried sample hydromethanolic extract. This extract showed the second strongest antibacterial activity, considering all the studied bacteria, after the other hydromethanolic extract. As the most resistant bacterial strain, $S$. typhimurium needed MIC and MBC values ranging from 1.85 to 15 and 3.75 to $30 \mathrm{mg} / \mathrm{mL}$, respectively. All the MIC and MBC values obtained for the positive controls were higher than those presented by the extracts. As far as we know, there are no reports on the antimicrobial activity of this plant infusions nor hydromethanolic extracts, which did not allow a comparison of the results obtained in the present study to other literature data. Nonetheless, an ethanol tincture of $G$. aparine desiccated stems produced an average zone of clearance of $2 \mathrm{~mm}$ (at a concentration of $27 \mathrm{mg} / \mathrm{mL}$ ), while aqueous extracts did not reveal activity against $S$. aureus, in a study performed by Romero et al. (2005) using Kirby-Bauer disk diffusion susceptibility analysis to assess the antimicrobial activity. Otherwise, Zhao et al. (2006) investigated the antimicrobial activity of 2,5-dihydroxy-1,3-dimethoxyanthraquinone isolated from an G. verum ethanolic extract, through the filter paper method, and reported a moderate activity against E. coli $(12 \mathrm{~mm})$, Salmonella aureus $(14 \mathrm{~mm})$, Pseudomonas aeruginosa $(13 \mathrm{~mm})$, and $S$. typhimurium $(14 \mathrm{~mm})$. Moreover, various Galium mexicanum aerial parts extracts (chloroform and methanol extracts) and fractions (hexane, chloroform, and methanol fractions) were found to possess antimicrobial activity against Bacillus subtilis, methicillin-resistant $S$. aureus, $S$. aureus, and Streptococcus pyogenes, in concentrations ranging from 166 to $666 \mu \mathrm{g} / \mathrm{mL}$, except for the hexane fraction that inhibited $S$. aureus growth at $67 \mu \mathrm{g} / \mathrm{mL}$ (Bolivar et al., 2011).

In what concerns the antifungal activity of $G$. aparine extracts, eight fungi were assessed: $A$. fumigatus, $A$. versicolor, $A$. ochraceus, $A$. niger, $C$. krusei, $P$. funiculosum, $P$. ochrochloron, and $P$. verrucosum. Similar to the results obtained in the antibacterial activity assessment, the hydromethanolic extracts also revealed higher antifungal activity than the infusions, with the freeze-dried sample showing the lowest MIC and MFC values, which ranged from 1.85 to 15 and 3.75 to $20 \mathrm{mg} / \mathrm{mL}$, respectively. The freeze-dried sample infusion showed the capacity to inhibit the growth of $A$. versicolor, A. ochraceus, and $P$. funiculosum, in concentrations of $7.5,15$, and $30 \mathrm{mg} / \mathrm{mL}$, respectively, and also presented fungicidal properties in A. versicolor and A. ochraceus (MFC values of 15 and 30, respectively). On the other hand, the air-dried sample infusion showed MIC values of $15 \mathrm{mg} / \mathrm{mL}$ in $A$. versicolor and $A$. ochraceus, and $30 \mathrm{mg} / \mathrm{mL}$ in A. fumigatus, C. krusei, $P$. funiculosum, $P$. ochrochloron, and $P$. verrucosum, but did not present fungicidal activity at the tested concentration $(30 \mathrm{mg} / \mathrm{mL})$. All the studied fungi were sensitive to the hydromethanolic extracts and the major differences 
between MIC and MFC values were observed for $P$. verrucosum in the presence of the air-dried sample hydromethanolic extract, where MFC $(30 \mathrm{mg} / \mathrm{mL}$ ) was the triple of the MIC value. The antifungal activity of the positive controls was higher than that of the extracts, but both hydromethanolic extracts presented MIC and MFC values close to those obtained for ketoconazole (positive control 1) in what concerns $P$. ochrochloron and A. ochraceus, respectively.

To the best of our knowledge, this is the first work on the antifungal activity of G. aparine extracts. Nevertheless, Bolivar et al. (2011) studied G. mexicanum extracts and fractions and demonstrated the ability of some hexane and methanol fractions to inhibit the growth of Trichophyton rubrum and Cryptococcus neoformans, when concentrated at 333-500 and 333-999 $\mu \mathrm{g} / \mathrm{mL}$, respectively, while a chloroform fraction exhibited activity in Candida albicans at $666 \mu \mathrm{g} / \mathrm{mL}$; none of the assessed extracts (chloroform and methanol extracts) revealed antimicrobial properties. Similarly, G. verum methanolic extracts did not reveal antifungal activity in a study performed with several Candida species (Yiğit et al., 2009), contrarily to G. aparine hydromethanolic extracts assessed in the present study that showed the capacity to inhibit the growth of eight fungi, also revealing fungicidal properties.

\section{Conclusion}

Four extracts (two hydromethanolic extracts and two infusions) of G. aparine samples subjected to different drying procedures (freezedrying and air-drying) were assessed for their phenolic profile and related bioactive properties. Generally, the samples presenting the highest levels of phenolic compounds also demonstrated higher bioactive properties. The freeze-dried sample hydromethanolic extract was the outstanding extract in terms of total phenolic concentration, antioxidant, antibacterial, and antifungal properties. None of the extracts revealed hepatotoxicity. The present study provides valuable information regarding $G$. aparine, contributing to the valorization of this Galium species, commonly known as an undesired and troublesome weed in several cultivars, and which previous reports are scarce.

\section{Acknowledgements}

The authors are grateful to the Foundation for Science and Technology (FCT, Portugal) and FEDER under Programme PT2020 for financial support to CIMO (UID/AGR/00690/2013); to FCT for L. Barros research contract; to FCT for the grant attributed to C. Pereira (SFRH/BPD/122650/2016) through the Programa Operacional Capital Humano (POCH) supported by the European Social Fund and National Funds of MCTES (Ministério da Ciência, Tecnologia, e Ensino Superior); and to FEDER-Interreg España-Portugal programme for financial support through the project 0377_Iberphenol_6_E. The authors are also grateful to the Serbian Ministry of Education, Science and Technological Development, grant number 173032 for financial support.

\section{References}

Abbasi, A.M., Shah, M.H., Li, T., Fu, X., Guo, X., Liu, R.H., 2015. Ethnomedicinal values, phenolic contents and antioxidant properties of wild culinary vegetables. J. Ethnopharmacol. 162, 333-345.

Aslantürk, Ö., Celik, T., Karabey, B., Karabey, F., 2017. Active phytochemical detecting, antioxidant, cytotoxic, apoptotic activities of ethyl acetate and methanol extracts of Galium aparine L. Br. J. Pharm. Res. 15, 1-16.

Bessada, S.M.F., Barreira, J.C.M., Barros, L., Ferreira, I.C.F.R., Oliveira, M.B.P.P., 2016. Phenolic profile and antioxidant activity of Coleostephus myconis (L.) Rchb.f.: an underexploited and highly disseminated species. Ind. Crops Prod. 89, 45-51.

Bokhari, J., Khan, M., Shabbir, M., Rashid, U., Jan, S., Zai, J.A., 2013. Evaluation of diverse antioxidant activities of Galium aparine. Spectrochim. Acta Part A Mol. Biomol. Spectrosc. 102, 24-29.

Bolivar, P., Cruz-Paredes, C., Hernández, L.R., Juárez, Z.N., Sánchez-Arreola, E., Av-Gay, Y., Bach, H., 2011. Antimicrobial, anti-inflammatory, antiparasitic, and cytotoxic activities of Galium mexicanum. J. Ethnopharmacol. 137, 141-147.

CABI, 2018. Invasive Species Compendium. [WWW Document]. URL https://www.cabi. org/isc/datasheet/24772 (Accessed 2 February 18).

Clifford, M.N., Johnston, K.L., Knight, S., Kuhnert, N., 2003. Hierarchical scheme for LC-MSn identification of chlorogenic acids. J. Agric. Food Chem. 51, 2900-2911.

Clifford, M.N., Knight, S., Kuhnert, N., 2005. Discriminating between the six isomers of dicaffeoylquinic acid by LC-MSn. J. Agric. Food Chem. 53, 3821-3832.

Deliorman, D., Çalis, I., Ergun, F., 2001. Iridoids from Galium aparine. Pharm. Biol. 39, 234-235.

Füleky, G., 2009. Cultivated Plants, Primarily As Food Sources Vol. 1 Eolss Publishers Co Ltd.

Fabricant, D.S., Farnsworth, N.R., 2001. The value of plants used in traditional medicine for drug discovery. Environ. Health Perspect. 69-75.

Fennell, C.W., Lindsey, K.L., McGaw, L.J., Sparg, S.G., Stafford, G.I., Elgorashi, E.E., Grace, O.M., van Staden, J., 2004. Assessing African medicinal plants for efficacy and safety: pharmacological screening and toxicology. J. Ethnopharmacol. 94, 205-217.

Goryacha V, O., Ilyina V, T., Kovalyova V, A.M., Kashpur V, N., 2014. Phytochemical research of Galium aparine L. Lipophilic complex and study of its antibacterial activity. Pharma Innov. J. 3, 7-10.

Guimarães, R., Barros, L., Dueñas, M., Calhelha, R., Carvalho, A., Santos-Buelga, C., Queiroz, M., Ferreira, I., 2013. Nutrients, phytochemicals and bioactivity of wild Roman chamomile: a comparison between the herb and its preparations. Food Chem. 136, 718-725.

Haq, N., 1993. New plant-derived ingredients. Technology of Reduced-Additive Foods. Springer, US, Boston, MA, pp. 139-159.

IUPAC, 1976. Nomenclature of cyclitols. Biochem. J.

Jyotsna, S., Katewa, S.S., 2016. A review: underutilized wild edible plants as a potential source of alternative nutrition. Int. J. Bot. Stud. 1, 32-36.

Lindsey, K.L., Motsei, M.L., Jager, A.K., 2002. Screening of South African food plants for antioxidant activity. J. Food Sci. 67, 2129-2131.

Malik, N., Born, W.H. Vanden, 1988. The biolology of Canadian weeds.: 86. Galium aparine L. and Galium spurium L. Can. J. Plant Sci. 68, 481-499.

Mocan, A., Crișan, G., Vlase, L., Ivănescu, B., Bădărău, A.S., Arsene, A.L., 2016. Phytochemical investigations on four Galium species (Rubiaceae) from Romania. Farmacia 64, 95-99.

Morreel, K., Saeys, Y., Dima, O., Lu, F., Van De Peer, Y., Vanholme, R., Ralph, J., Vanholme, B., Boerjan, W., 2014. Systematic structural characterization of metabolites in arabidopsis via candidate substrate-product pair networks. Plant Cell 26, 929-945.

Moubasher, H., Abd El-Ghani, M., Al-Wakeel, S., Bahoor, A., 2016. Chemotaxonomic significance of flavonoids in some species of Galium (Rubiaceae) from Libya. Austin J. Plant Biol. 2, 1014-1021.

Pandey, K.B., Rizvi, S.I., 2009. Plant polyphenols as dietary antioxidants in human health and disease. Oxid. Med. Cell. Longev. 2, 270-278.

Rita, I., Pereira, C., Barros, L., Santos-Buelga, C., Ferreira, I.C.F.R., Araújo, M.E.M., Sotnikova, R., Crisan, G., Pierre, D., 2016. Mentha spicata L. infusions as sources of antioxidant phenolic compounds: emerging reserve lots with special harvest requirements. Food Funct. 7, 4188-4192.

Romero, C.D., Chopin, S.F., Buck, G., Martinez, E., Garcia, M., Bixby, L., 2005. Antibacterial properties of common herbal remedies of the Southwest. J. Ethnopharmacol. 99, 253-257.

Soković, M., Van Griensven, L.J.L.D., 2006. Antimicrobial activity of essential oils and their components against the three major pathogens of the cultivated button mushroom, Agaricus bisporus. Eur. J. Plant Pathol. 116, 211-224.

Soković, M., Glamočlija, J., Marin, P.D., Brkić, D., van Griensven, L.J.L.D., 2010 Antibacterial effects of the essential oils of commonly consumed medicinal herbs using an in vitro model. Molecules 15, 7532-7546.

Svobodova, B., Barros, L., Calhelha, R.C., Heleno, S., Alves, M.J., Walcott, S., Bittova, M., Kuban, V., Ferreira, I.C.F.R., 2017. Bioactive properties and phenolic profile of Momordica charantia L. medicinal plant growing wild in Trinidad and Tobago. Ind. Crops Prod. 95, 365-373.

Taskin, T., Bitis, L., 2016. In vitro antioxidant activity of eight wild edible plants in Bursa province of Turkey. Farmacia 64, 706-711.

Tobyn, G., Denham, A., Whitelegg, M., Rowling, M., 2016. The Western herbal tradition: 2000 years of medicinal plant knowledge. Singing Dragon.

Vlase, L., Mocan, A., Hanganu, D., Benedec, D., Gheldiu, A., Crişan, G., 2014. Comparative study of polyphenolic content, antioxidant and antimicrobial activity of four Galium species (Rubiaceae). Dig. J. Nanomater. Biostruct. 9, 1085-1094.

Yiğit, D., Yiğit, N., Özgen, U., 2009. An investigation on the anticandidal activity of some traditional medicinal plants in Turkey. Mycoses 52, 135-140.

Young, I.S., Woodside V, J., 2001. Antioxidants in health and disease. J. Clin. Pathol. 54, $176-186$.

Zhao, C.C., Shao, J.H., Li, X., Xu, J., Wang, J.H., 2006. A new anthraquinone from Galium verum L. Nat. Prod. Res. 20, 981-984. 